\title{
e-Business strategy and firm performance: a latent class assessment of the drivers and impediments to success
}

\author{
Tim R Coltman ${ }^{1}$, Timothy M Devinney ${ }^{2}$ and David F Midgley ${ }^{3}$ \\ ${ }^{1}$ School of Information Technology and Computer Science, University of Wollongong, Wollongong, NSW, Australia \\ ${ }^{2}$ Australian Graduate School of Management, University of NSW, Sydney, Australia; \\ ${ }^{3}$ Marketing Area, INSEAD, Fontainebleau, France \\ Correspondence: \\ Dr T R Coltman, School of Information Technology and Computer Science, University of Wollongong, Northfields Road, \\ Wollongong, NSW 2522, Australia. \\ Tel: +61242213912 . \\ Fax: + 6129313 7279; \\ E-mail: tim_coltman@uow.edu.au
}

\begin{abstract}
Among many leading organizations, in all sectors of industry, commerce and government, there is considerable evidence of e-business being deployed to achieve strategic goals. Where this deployment has been most successful, there is a strong case that the organization has taken an integrated approach that both builds on the organization's strengths and pays careful attention to the process of change within the organization. However, in the literature most empirical work has either studied e-business strategy and performance from the perspective of strategy content - which highlights positioning and/ or unique bundles of resources - or from the perspective of strategy process - which captures human influence and e-business implementation. In this study, we integrate these two perspectives to develop a more holistic understanding of the underlying drivers of e-business performance. Further, latent class modeling techniques are used to show that the variables in our study are heavily influenced by the unobservable heterogeneity across firms. Four distinct types of firms populate our data, and the relationship between performance and its underlying determinants varies greatly between them. The implication is that a single model cannot explain the relationship between environment, structure, feasibility, managerial beliefs and performance. This is critical to our understanding of e-business as it implies that there is far less homogeneity at the individual firm level than is normally assumed in the literature.
\end{abstract}

Journal of Information Technology (2007) 22, 87-101. doi:10.1057/palgrave.jit.2000073

Published online 10 October 2006

Keywords: e-business strategy; information technology; performance; latent class models

\section{Introduction}

D espite the dot.com collapse, there remains a strong belief that e-business - with its resurgent potential for creating new transactional opportunities between firms, suppliers, complementary product/service providers and customers - will ultimately contribute significantly to the future performance of many established firms. A number of impressive examples come to mind: Tesco in the UK, Otto Versand in Germany, and Dell Computers and Cisco Systems in the US. ${ }^{1}$ For organizations such as these, e-business is more than a tool but part of a deeply held strategic disposition that enables them to outperform the competition. ${ }^{2}$ Yet, in spite of these high-profile success stories many other similarly situated firms have failed to duplicate these results. This is not altogether surprising as technology innovation theory predicts that within any population there are substantially more imitators than early adopters (DiMaggio and Powell, 1983; Swanson and Ramiller, 1997). For those imitators wanting to learn from these role models, a number of important questions come to mind, two of which, are the focus of this study:

- Why does performance (specifically that related to ebusiness) vary between organizations that operate within 
the same line of business and have access to the same information and technologies?

- To what extent are these differences structural - that is, driven by firm resources and infrastructure - or cognitive - that is, driven by the beliefs and commitment of managers to a specific future (in this case a future implying e-business implementation)?

Both questions are of practical importance because they tap into the organizational reasoning that takes place to explicate and justify e-business applications. Unraveling this reasoning is also of theoretical importance to the information technology (IT) literature in that it underlies the extent to which organizational success is determined by strategy content and/or process. ${ }^{3}$ Although intuitively linked to one another, the content and process perspectives have evolved independently (see Rajagopalan and Spreitzer (1996) for an extensive review).

For example, a large body of content research shows that various structural considerations influence performance. These antecedents are both external and internal to the firm. The former is defined by economic, technological, political and competitive forces (Pettigrew, 1992) and the later by core competencies (Hamel and Prahalad, 1994) and dynamic capabilities (Teece et al., 1997). Both the external and internal schools of thought have been used to explain variation in IT-related performance (e.g., Porter, 2001; Wade and Holland, 2004).

The process school of thought is concerned with those activities leading to and supporting a choice of strategy (Huff and Reger, 1987) and its implementation (Thompson and Strickland, 2001). Explaining 'how' strategy should be executed is the role of process research. This approach seeks the richness of a more multidimensional approach by incorporating results obtained typically through managerial beliefs and perceptions in distinguishing the significant from the irrelevant aspects of environmental change and the set-up and take-down costs incurred when responding to market pressures (Carson et al., 1999). Explaining 'how' learning and project execution comes about has traditionally been a focus of applied disciplines such as IT (Clemons and Weber, 1990).

It is particularly noteworthy that few studies of ebusiness have sought to integrate these different views. This is despite concerns that, on their own, the dominant schools of thought may actually serve to impede or inhibit rather than illuminate reality in a meaningful way (Varadajan, 1999; Chan, 2000). Conceivably this is because of artificial separations of phenomena that are in reality interwoven. The implication of this for e-business strategy and implementation is that academics and practitioners alike are prone to overstate their ability to identify the full impact of technology and to underestimate the challenge of developing and implementing an effective e-business strategy.

The complex nature of e-business also has implications for how we might develop empirically testable models that identify the underlying drivers of performance. For example, Hatten et al. (1978) have demonstrated that indiscriminant data pooling of firms and industries can mask the very essence of strategy and the key contributors that make a difference to performance. The implication of this insight is that studies based on aggregated data and looking for singular models that explain performance must be viewed cautiously, both for theoretical and statistical reasons. What is needed is a more sophisticated approach that moves beyond data pooling and aggregation techniques, towards approaches that enable us to capture the heterogeneity that actually exists in modern business. This paper utilizes such an approach based on latent class modeling.

Latent class modeling is a segmentation-based approach that is particularly relevant for the study of unsettled environments such as those operating within the e-business realm for two reasons. First, the evolving and immature nature of the e-business environments in which firms are operating, and their differential reactions to those environments, are more likely to permit the existence of different and sustainable economic models over an appreciable length of time. Second, it is likely that firms facing the same external pressures must overcome unique internal financial, business and organizational constraints, and their success at doing so will differ. This heterogeneity is in line with the theoretical assumptions underlying the resourcebased view of the firm (Wernerfelt, 1984; Barney, 1991) and arises because of the differential influence of history and environment, for example, path dependence, causal ambiguity and dynamic capabilities (Teece et al., 1997).

The remaining sections of this paper set about testing a general model of e-business performance, which, after accounting for the pressures facing the firm, explains why and how the adoption of e-business should lead to operational and competitive advantage. We develop four hypotheses and test their importance using field interviews and a survey of 293 organizations. Our results indicate that heterogeneous demands and conditions characterize the business environment, creating differential pressures for change and significant variance in the performance outcomes of such change.

\section{The IT performance question}

Most organizations, in all sectors of industry, commerce and government, are fundamentally dependent upon information systems (IS). Consequently, organizations have assumed that advances in IT infrastructure and e-business systems will not only provide economic returns, but are an important element of business definition and competitive strategy (Johnston and Carrico, 1988; Bharadwaj, 2000; Santhanam and Hartono, 2003). However, two decades of IT performance research has shown that the link between IT investment and improved organizational performance is still elusive (for a review, see Chan, 2000).

Time and again, uncertainty and debate has characterized the IS literature regarding what we know and do not know about the IT payoff. For example, 'productivity paradox' proponents claim that despite the massive investment in IT, these systems have not produced significant improvements in industrial productivity (Thurow, 1991; Brynjolfsson, 1993). The frustration professionals experienced with IT and its impact on performance has led to considerable hand-wringing and erosion of IT credibility in the board room prompting Blake Ives to make the following editorial comment in MIS Quarterly: 
It is the obligation of every IS professional to understand the issues that surround the paradox... and each of us must then be prepared and willing to participate knowledgeably in the debate (Ives, 1994: 21-22).

More recent reviews of IT productivity have produced encouraging results. Brynjolfsson and Hitt (1998) conclude that IT is valuable, even though its extent and dimension varies across organizations. Barua et al. (2004) report that online informational capabilities lead to better financial performance and Santhanam and Hartono (2003) find that superior IT capability is associated with improved performance. The received wisdom on IT business value can thus be summarized as follows: if the right IT is applied in the right way, improved business performance will result, conditional upon appropriate complementary investments in workplace practices and organizational structures and shaped by the competitive environment (Melville et al., 2004).

Additionally, there is some evidence to suggest that the fragmented and inconsistent observations reported in the literature can be attributed to two problems that reflect the focus of this research. The first is that simple prescriptions are of limited value because they fail to capture the reality that e-business performance depends upon the confluence of strategic and tactical contingency factors. This requires scholars to consider managerially relevant models of the firm that cut across traditional boundaries to bridge the divide between what e-business strategy should be developed - that is, strategy content - and the challenges regarding how e-business strategy is implemented - that is, strategy process. The second is that we require empirically testable frameworks and techniques that accurately reflect the considerable heterogeneity in modern business. Whether as a direct, mediator or moderator, there are many complementary organizational resources such as workplace practices, skills and structures that interact with IT in the attainment of organizational performance.

\section{A conceptual model of e-business performance: merging strategy content and process}

Our conceptual model is based on a unifying framework first developed by Devinney et al. (2000). In developing this framework, the authors first expand on the industrial organization tradition where environmental pressures determine what the market will allow. Second, they capture what is possible given existing resources and capabilities. Third, they integrate into their theory the ways in which managers react to business opportunities; managerial beliefs tell us what the manager's think is the correct thing to do (independent of what the firm can do). Lastly, issues of institutional feasibility define what the firm can actually do. Thus, by separating strategic pressures and capabilities (strategy content) from managerial decisions and organizational constraints (strategy process), a clearer understanding of the nature and evolution of business performance is revealed.

Expanding on these points, we will now derive two hypotheses from the strategy content literature and two from the strategy process literature.
Hypotheses derived from the strategy content literature

We begin by integrating the early work that has directed scholarly attention towards the importance of market and environmental dynamics. This literature in industrial organization is voluminous and draws heavily on Michael Porter's (1985) seminal work. The relevance of this work to e-business is most visible in the Harvard Business Review paper titled 'Strategy and the Internet' (Porter, 2001). For the sake of brevity, we focus on one other illustrative example, Johnston and Carrico (1988). Their study of 11 industries found that external pressures played a significant role in explaining the link between IT implementation and performance. Industry factors acted as catalysts that set off serious attempts to exploit IT for competitive advantage in airline, financial services and distribution companies. In less competitive industries (e.g., oil or office equipment), executives did not perceive a need for an all-out effort to build IT advantages. The implications for e-business are that if there is no significant pressure in the external environment for change, then the firm has little incentive to alter its activities significantly. We therefore hypothesize the following:

Hypothesis 1: Organizations facing greater environmental pressures for e-business are best positioned to capture performance returns.

Another important aspect of business strategy is that the path to fit is not always externally driven but can arise from internal factors (Henderson and Venkatraman, 1993). This conception complements the resource-based view of the firm, which emphasizes the importance of unique bundles of firm-specific resources (Barney, 1991) and distinctive capabilities acquired over time (Teece et al., 1997). Building on this literature, several authors have found empirical relationships between superior IT resources and performance (e.g., Bharadwaj, 2000; Wade and Holland, 2004). However, the empirical challenge has been to develop operationally sound criteria for distinguishing between important resources and capabilities (Priem and Butler, 2001). To this point, signs of a general consensus have begun to emerge that are well represented in Tippins and Sohi's (2003) work. These authors define IT competency as consisting of: (1) technical knowledge about IT systems; (2) the extent to which the firm uses IT; and (3) the number of IT-related artifacts. This work enables one to posit that firms with high IT capabilities will tend to outperform competitors (without these capabilities) on a variety of profit- and cost-based performance measures. This reasoning allows us to hypothesize the following:

Hypothesis 2: Organizations with high levels of IT infrastructure, skills and online activity are best positioned to capture e-business performance benefits.

Hypotheses derived from the strategy process literature This literature emphasizes that the way managers perceive their environment and their company's place in it has a long-lasting impact on their behavior (Child, 1972; Finkelstein and Hambrick, 1996). Managerial beliefs and 
cognitive schemas capture a manager's understanding of their work situation. The importance of this can be seen in a major study by CSC Index (1994) that found a strong correlation between managerial beliefs and the success of reengineering change programs. CSC's research concluded that reengineering programs with 'breakthrough' or 'revolutionary' beliefs were more likely to succeed than those with modest objectives. The authors of the report conclude that modest beliefs provide insufficient incentive to make the necessary changes in organization, processes, training and reward systems that this type of change requires. These findings are consistent with the technology adoption literature where managerial beliefs regarding technology expectations mediate all other variables (Lewis et al., 2003).

Collectively, these findings indicate that it is not only operating capabilities or market power that generates organizational rents but the difficult to predict interpretations of boundedly rational managers to the perceived need for strategic change plays a significant role also. Modest managerial beliefs, legitimacy motivations or a general failure to view IT as strategic, is unlikely to deliver the organizational change that e-business requires. Rather, strongly held beliefs are required to deal with organizational change and IT implementation issues (Venkatraman, 1997). The following testable hypothesis is derived from this argument:

Hypothesis 3: Managerial beliefs mediate the link between strategy content and e-business performance.

The preceding three hypotheses present a structure where finding the right e-business strategy is dependent upon ITspecific organizational capabilities, the external environment and managerial perceptions. Yet, the formulation of a truly successful strategy requires managers to overcome organizational inertia that limits its ability to execute whatever strategy it chooses (Aspesi and Vardham, 1999). The 'neo-institutionalist' approach emphasizes that institutional facilitators of, and constraints to, the implementation of strategy make some forms of strategic change more 'available' to some firms than others.
The implication is that, in the best of circumstances managers cannot expect to be making first best choices. All a manager can hope for is a 'remedially efficient' arrangement - one that represents the best that can be achieved given the limitations of all the affected players and the costs of setting up the new and undoing the old arrangement. The concept of remedial efficiency is relevant to e-business because: (1) it accounts for the uncertainty associated with what is a correct business model, (2) it reflects the fact that there are large set-up and take-down costs in implementing any institutional structure encompassing the Internet, (3) it focuses attention on the fact that there are many players in an arrangement, all of whom must bear some cost if the arrangement is to be successful and (4) it accounts for those overarching macro-institutional arrangements (legal systems, broadband, etc.) that will impact on issues (1)-(3).

What has been shown to work for one organization might be desirable for managers of others, but may in fact be unattainable when feasibility constraints are taken into account. From our perspective, these constraints are compartmentalized into three general issues: (1) organizational inertia, (2) financial constraints and (3) operational implementation. The following testable hypothesis is derived from this argument:

Hypothesis 4: When organizational constraints (organizational, financial and implementation) are low, e-business performance is high.

Next, we derive a set of operational indicators that directly relate to the theoretical dimensions, and then, test our empirical model.

\section{Empirical model and methodology}

\section{Model setup}

The schematic in Figure 1 captures Hypotheses 1-4 and presents a testable model of e-business performance based on the interaction of structural, organizational and

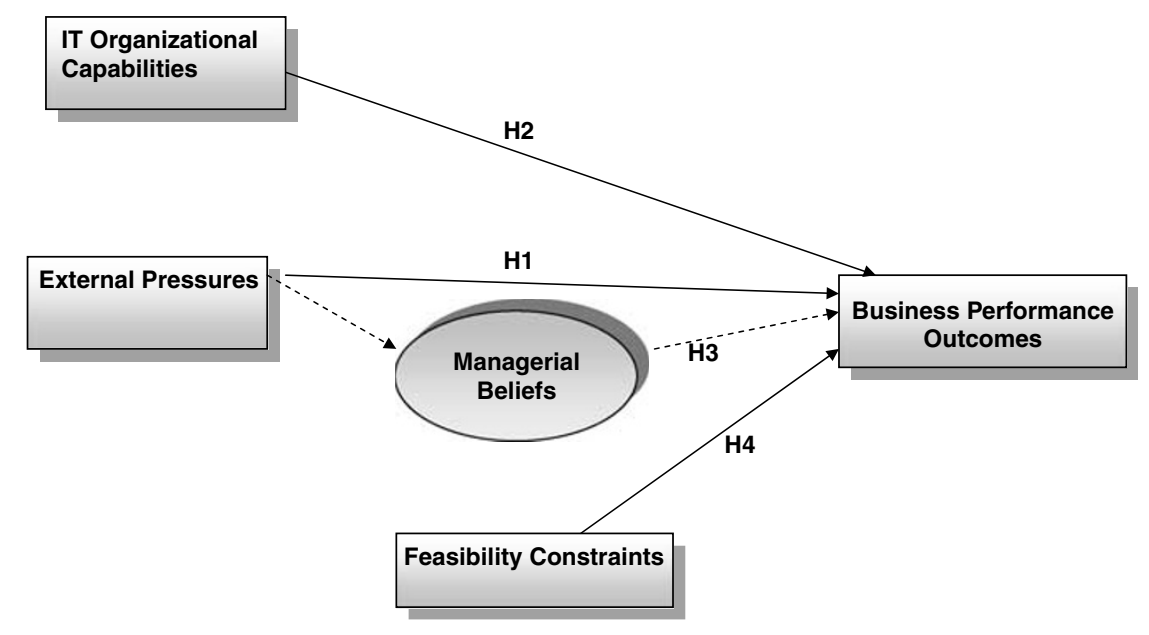

Figure 1 Hierarchical Model and Measures of e-Business Orientation Model. 
managerial factors. According to the model, the beliefs held by managers mediate two sets of pressures driving ebusiness performance: (1) the environmental pressures which represent the market, technological and environmental pressures to move online - and (2) the feasibility constraints. The organizational conditions serve to adjust for heterogeneity across organizations possessing different internal assets and capabilities that may impact on ebusiness performance.

We apply two sets of empirical analyses to understand the relationships in our model. The first analysis is a simple ordinary least-squares (OLS) regression to determine whether or not the model proposed operates in the aggregate. Our intuition suggests that the influence of internal and external pressures will operate both directly and indirectly through managerial beliefs. We test this mediating effect using the procedure proposed by Baron and Kenny (1986). The second analysis applies latent class finite-mixture regression modeling techniques (assuming mixtures of normal distributions) to determine whether different forms of the model apply to different groups within the sample. This segmentation-based approach is further verified using discriminant analysis.

\section{Instrument development and measures}

Using the strategic business unit as the level of analysis, we developed all scales using an extensive and recursive pretesting procedure. A series of 54 in-depth interviews with senior managers was used to learn first-hand how ITrelated activities are being used to drive e-business performance. From these in-depth interviews and theoretical considerations, our scales were then developed and tested by academic experts for face validity and representativeness. These scales were then further pre-tested with senior managers and refined to ensure respondents were capable of answering the questionnaire. Appendix A provides a more descriptive list of the items and scales used in the study.

Note that we use a mixture of reflective, formative and single-item scales as appropriate to our purposes. Where it is theoretically justifiable to envisage a latent construct (e.g., 'managerial beliefs'), we use reflective scale development methods from psychology. Where it is not justifiable to envisage such a latent construct (e.g., 'IT infrastructure'), we form overall indices using index construction methods from economics. Chin (1998) discusses the distinction between these two approaches both of which have a legitimate role in empirical research. And where a singleitem measure will serve our purpose best, we use it following the advice of Rossiter (2002).

The fusion of IT and e-business into various aspects of work makes it difficult to obtain objective performance measures on the e-business components of business unit operations, nor is the impact of e-business identified in the typical accounting measures available for such business units. For this reason, it was necessary to gather performance data through self-report surveys. As advocated by Venkatraman and Ramanujam (1986), we adopt a broad conceptualization of performance that captures productivity and profitability (Kohli and Devaraj, 2003). The profitability component of performance comprised six measures: return on investment, market share, annual growth in revenue, total sales, and reduction in operating and production costs (Cronbach's alpha, $\alpha=0.91$ ). Five items were used to derive an operational productivity measure across various strategic dimensions: the ability of e-business to offer new customer insights, to target the most profitable customers, to work faster, more flexibly and with greater precision and control $(\alpha=0.80)$. Since these measures are correlated and proportional to each other, we combine them into one scale that measured overall performance dimensions $(\alpha=0.82)$.

Empirical studies have consistently shown that external pressures create strong drivers for change in organizations. In this study, we chose not to replicate these complex measures. Rather, our interest is in the existence of environmental pressures and not their specific characteristics. This construct was measured using a single item - ' $[\mathrm{t}] \mathrm{o}$ what extent are market, technological, and environmental pressures moving the firm towards more or less online products and/or services?' As noted by Rossiter (2002), there is no problem in using a single-item measure when respondents understand clearly that only one characteristic is being referred to in the question. These measures are referred to as concrete singular and can be captured adequately using single-item measures.

A key feature of established firms is that they have readily identifiable organizational capabilities that are both tangible (e.g., physical IT infrastructure) and intangible (e.g., reflected in human know-how). From the perspective of this research, we assume a high correlation between the importance of knowledge to the firm and the allocation of resources to ensure sufficient levels of knowledge in the firm. Respondents were asked to indicate the 'extent [to which] IT know-how [was] important to [their] business unit'.

Drawing on prior work (Tippins and Sohi, 2003) IT infrastructure was measured across multiple areas. First, we derived the number of IT artifacts and their level of usage. E-mail systems, ERP applications, Intranet applications and Internet applications were included. Then we combined these items into a single formative index reasoning that there is no latent construct of 'IT infrastructure' rather what we need to measure is an index of the overall level of usage of these artifacts. No inter-item correlations were calculated because the individual items in formative indices are expected to be relatively independent, making consistency measures such as Cronbach's alpha inappropriate (Chin, 1998). IT know-how importance was used to operationally capture knowledge about IT systems.

Lastly, simply implementing sophisticated IT systems and generating systems know-how will have little impact on performance unless action is taken. We measure action using a formative index that captures online activity of each firm in our study. Online activity was determined using a 10 -point scale measuring the amount of business activity (B2C, B2B and B2G) conducted electronically. Again, the point of using a formative measure is to obtain an overall index that allows us to compare bricks and mortar activities with e-business activity.

Managerial beliefs were measured by asking respondents to rate the extent to which they believe that e-business systems will create new operational and strategic benefits. 
Drawing on prior work that has sought to operationalize managerial beliefs (Coltman et al., 2005) and our qualitative interviews, we develop a scale based on five items that captures managerial beliefs regarding e-business and (1) the current competitive standing of the firm, (2) relationships with major customers/partners, (3) the creation of new value for customers/partners, (4) the opportunity to create joint profit with partners and (5) the long-run value of the firm. As these items reflect the construct of overall managerial beliefs with respect to e-business activity, they are combined into a multi-item reflective scale $(\alpha=0.72)$.

Three separate items were used to measure organizational and technical feasibility constraints: (1) financial constraints entailed in setting up new e-business operations, (2) the organizational and political constraints incurred in setting up and taking down complex IT systems and (3) the operational implementation issues incurred in terms of security, reliability and privacy considerations. As all these items were viewed as reflecting the underlying constructs, they were aggregated. Financial constraints were measured using two items capturing hard costs (infrastructure) and soft costs (people and training) $(\alpha=0.82)$. Organizational constraints are measured using two items that capture the degree of difficulty in gaining consensus among key decisions makers and the role of political influence and parochial interest in the organization $(\alpha=0.70)$. Operational implementation issues are measured by the influence of network performance problems, information security, brand protection and customer privacy. The Cronbach alpha for this multi-item scale is 0.69 , which is within acceptable limits for exploratory research (Robinson et al., 1991).

A number of studies have shown that firms with more advanced states of implementation can expect greater performance returns than those with relatively immature states of implementation (e.g., Chircu and Kauffman, 2000). Differences in the state of e-business implementation range from 'the pilot program stage' to 'successful integration into core systems' to having 'been wound down because they have proven to be unprofitable.' Two dummy coded variables were created to control for these difference in the state of e-business implementation. Further, studies in structural contingency theory indicate that firm size, industry type and corporate orientation strongly influence performance. To control for these effects we created dummy coded variables; however, no statistically significant results were obtained.

To ensure the validity of our measures, we examined key informant bias, non-response bias, common method bias, dimensionality and convergent and discriminant validity. For the sake of brevity we have provided a short summary only. Senior managers were targeted from three functional areas (IT, marketing and strategy), reducing the impact of key informant bias. Based on responses obtained from a short web-based form sent to all non-respondents, the risk of non-response bias was not considered high. Twenty-five per cent of respondents indicated that they were not interested in completing the questionnaire, $10 \%$ said the survey was not applicable to their firm and a further $20 \%$ cited a range of reasons why they did not complete the form (the questionnaire is too long, we receive too many of these questionnaires with little apparent benefit, etc.). To test for common method bias, we applied Harmann's ex post onefactor test (Podsakoff and Organ, 1986) across the entire survey, which includes the measures used here. Thirty-eight distinct factors were needed to explain $80 \%$ of the variance in the measures used, with the largest factor accounting for only $11 \%$ of the variance. Hence, there was no 'general factor' in the data that would represent a common method bias.

A correlation matrix of the constructs is shown in Table 1. For the reflective constructs, factor analyses of their underlying questionnaire items indicated one dimension for each, making it legitimate to compute the Cronbach alphas given earlier and to regard them as unitary constructs. We also computed the average variance extracted by these items (Fornell and Larcker, 1981). The fact that these average variances are all above 0.7 indicates adequate convergent validity for their underlying items. Furthermore, the fact that they are higher than the correlations between the various constructs indicates adequate discriminant validity between these constructs.

\section{Data collection method}

Our four hypotheses were tested using data collected by interviews and a cross-sectional survey of senior managers. The survey was mailed to 2,000 organizations selected from a stratified random sample of firms across seven industry sectors, namely: financial services, business services (including IT and telecommunications), government, retail, manufacturing, primary industries and transport/distribution. This cross-industry sample was selected to ensure that respondent firms vary in markets and technology environments, thereby improving the relevance and generalizability of our results.

The questionnaire was addressed to senior managers, with care taken to ensure respondent competency. The number of responses totaled 365 (giving an 18\% response rate). Several approaches were used to increase response rates: a personalized cover letter to all respondents, an offer to win a digital camera (worth nearly $\$ 500$ ) and an invitation to attend a seminar where the results were to be presented. ${ }^{4}$ Two reminder e-mails and follow-up phone calls were also used to improve response rates.

After eliminating responses due to (1) firms not using ebusiness or (2) large proportions of missing data, a final sample of 293 responses was used in the analysis. Industry distribution captures the main segments of e-business activity: business services $(39 \%)$, government $(20 \%)$, retail (11\%), manufacturing, agriculture and mining (30\%). Firm size was also well distributed, with $46 \%$ small- to mediumsized firms (less than 500 employees) and 54\% large firms (more than 500 employees). The mean and median sizes for the entire sample were 2,480 and 650 employees, respectively. To determine the impact of non-response bias in the study, $t$-tests were undertaken on the distribution of returned questionnaires relative to the sample. The results indicated no significant industry or size bias.

\section{Method of estimation}

Mixture models are useful in estimating the likelihood that a specific firm fits into a class of firms for which a particular model applies (see Wedel and Kamakura (2000) 


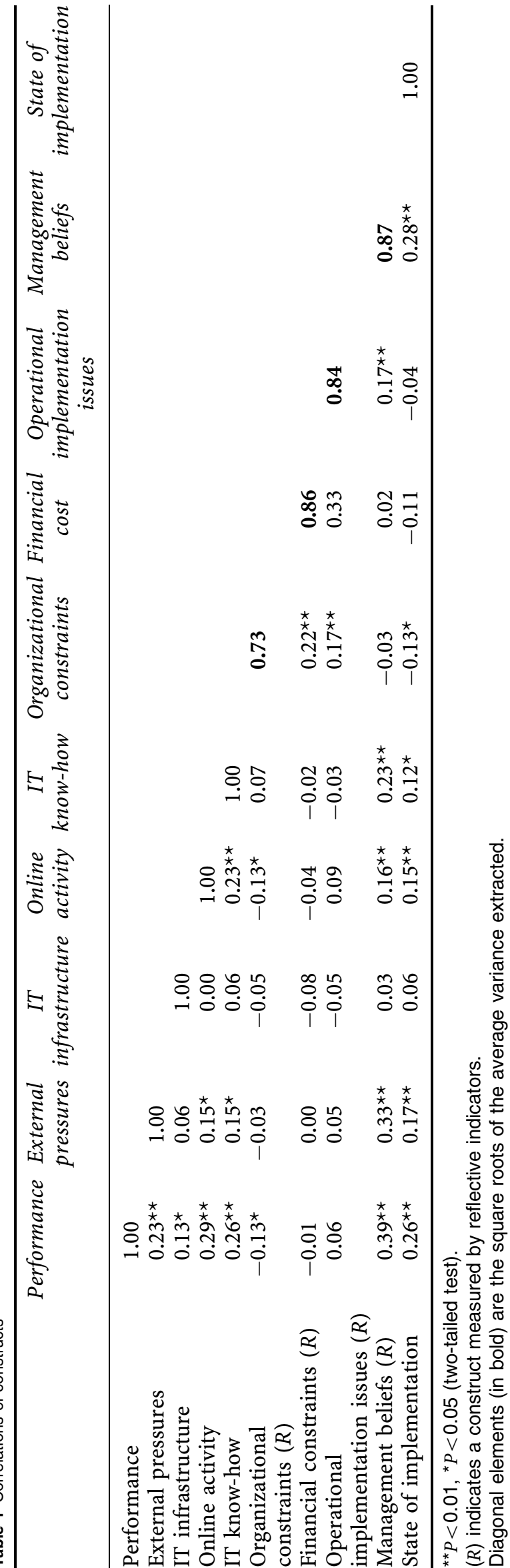

Table 2 Measures of model fit and parsimony by segment

\begin{tabular}{lccccc}
\hline & \multicolumn{5}{c}{ Number of segments } \\
\cline { 2 - 6 } & 1 & 2 & 3 & 4 & 5 \\
\hline Likelihood & -224.7 & -211.8 & -201.6 & -169.9 & -139.7 \\
AIC & 475.4 & 471.3 & 467.2 & $\mathbf{4 2 4 . 4}$ & 431.8 \\
CAIC & 522.9 & 577.1 & 637.9 & $\mathbf{6 3 3 . 4}$ & 673.9 \\
MAIC & 486.5 & 494.2 & 502.5 & $\mathbf{4 7 1 . 6}$ & 490.4 \\
NEC(S) & - & 0.021 & 0.016 & $\mathbf{0 . 0 1 3}$ & 0.008 \\
Entropy & 1.000 & 0.289 & 0.359 & $\mathbf{0 . 7 1 7}$ & 0.660 \\
$R^{2}$ & 0.13 & 0.41 & 0.78 & 0.90 & 0.95 \\
d.f. & 11 & 23 & 35 & 47 & 59 \\
\hline
\end{tabular}

Note: Bold items indicate either minimum (AIC, CAIC, MAIC, $\mathrm{NEC}(\mathrm{S})$ ) or maximum (Entropy) measures.

for recent applications; Lazarfeld and Henry (1968) is the original work and McCutcheon (1987) provides more general background). More specifically, with latent class modeling we are able to account simultaneously for both the similarity and differences between firms. It allows us to address alternative model structures (in the sense of different parameter estimates) and the extent to which an estimated model applies to any particular firm (through the estimation of posterior probabilities that a specific firm falls into a class for which the model is statistically appropriate) concurrently.

Like any clustering technique, the appropriateness of mixture models is determined first by theory and second by the ability to find meaningful and significant differences in the population at hand. There is no single criterion for the choice of the number of segments. One such set of criteria, known as information criteria, is based on assessing the degree of improvement in explanatory power adjusted for the number of degrees of freedom. The most common information criteria are the Akaike (1974) information criterion. The consistent Akaike information criterion is more conservative and is skewed to models with fewer segments as it imposes an additional sample size penalty. Results are shown in Table 2.

In addition to dealing with over parameterization as the number of segments increases, one needs to be assured that the segments are sufficiently distinctive. To do this, the estimated posterior probabilities of segment membership should be compared based on a normed entropy criterion that accounts for any separation in the estimated posterior probabilities. Ultimately no single criterion appears able to determine the 'correct' number of segments. One must rely on a number of criteria as well as the structure of the models arising and how they relate to the theory being tested.

\section{Results}

The results of the OLS and mixture regressions are presented in Table 3 with the effect size estimates shown in Table 4. The OLS estimates provide a basis of comparison to show the extent of heterogeneity in the data and what the failure to account for this implies. Based on the OLS results alone we find support for hypotheses 1,2 and 3. Firms can most likely expect significant e-business 
Table 3 Multiple regressions and latent class models on e-business performance

\begin{tabular}{|c|c|c|c|c|c|c|}
\hline & \multicolumn{2}{|c|}{ OLS estimates } & \multicolumn{4}{|c|}{ Latent class estimates } \\
\hline & & & Segment 1 & Segment 2 & Segment 3 & Segment 4 \\
\hline External pressures to move online & $0.092^{*}(1.676)$ & $0.620^{\star *}(2.253)$ & $1.70^{\star \star \star}(10.21)$ & $0.88^{\star * *}(3.53)$ & $-0.06(-0.44)$ & $1.04^{\star * *}(9.53)$ \\
\hline \multicolumn{7}{|l|}{ Organizational capabilities } \\
\hline IT know-how & $0.142^{\star *}(2.620)$ & $0.152^{\star \star *}(2.808)$ & $0.02(1.36)$ & $-0.04(-1.48)$ & $-0.03(1.65)$ & $0.17^{\star \star *}(9.42)$ \\
\hline IT infrastructure & $0.094^{*}(1.853)$ & $0.147^{\star * *}(2.795)$ & $0.08^{* * *}(4.18)$ & $0.14^{* * *}(5.15)$ & $0.11^{\star * *}(4.27)$ & $0.01(0.28)$ \\
\hline Online activity & $0.172^{\star * *}(3.207)$ & $0.141^{\star \star}(0.433)$ & $0.01(0.79)$ & $0.20^{\star * *}(20.67)$ & $-0.01(-1.49)$ & $-0.04^{* * *}(-3.51)$ \\
\hline Managerial beliefs & $0.274^{\star * *}(4.755)$ & $0.141(0.433)$ & $0.95^{\star * *}(4.92)$ & $-2.85^{\star * *}(-9.66)$ & $1.03^{\star * *}(4.60)$ & $0.35^{\star \star}(2.57)$ \\
\hline \multicolumn{7}{|l|}{ Feasibility constraints } \\
\hline Organizational & $-0.100^{*}(-1.874)$ & $0.204(0.647)$ & $0.49^{\star * *}(4.97)$ & $-2.54^{\star * *}(-12.94)$ & $-0.54^{\star \star \star}(-4.00)$ & $0.51^{\star * *}(5.92)$ \\
\hline Financial & $0.036(0.657)$ & $0.012(0.032)$ & $0.49^{\star * *}(3.65)$ & $-1.86^{\star * \star}(-10.31)$ & $1.26^{\star * *}(6.94)$ & $-0.47^{\star * *}(-3.61)$ \\
\hline Operational implementation issues (OII) & $0.023(0.418)$ & $0.071(0.171)$ & $-0.12(-0.67)$ & $4.95^{\star * *}(15.92)$ & $-0.75^{\star * *}(-3.55)$ & $0.25(1.75)$ \\
\hline State of implementation & $0.107^{\star}(1.948)$ & $0.090^{*}(1.694)$ & $0.02^{\star * *}(8.97)$ & $0.08^{\star * *}(-3.20)$ & $0.23^{\star * *}(8.68)$ & $-0.02(-1.38)$ \\
\hline \multicolumn{7}{|l|}{ Mediating effects } \\
\hline External pressures $*$ managerial beliefs & & $-0.180(-0.501)$ & $-0.20^{\star * *}(-6.05)$ & $-0.37 \star * \star(6.60)$ & $-0.04(-1.16)$ & $-0.16^{\star * *}(-6.45)$ \\
\hline External pressures $*$ org. constraints & & $-0.493(-1.355)$ & $-0.08^{*}(-2.18)$ & $0.41^{* * *}(7.76)$ & $0.36^{* * *}(8.86)$ & $-0.22^{* * *}(-9.17)$ \\
\hline External pressures $*$ financial costs & & $-0.764^{*}(-1.887)$ & $-0.12^{* * *}(-3.73)$ & $-0.05(1.43)$ & $-0.47^{\star * *}(-9.98)$ & $-0.05^{\star}(-1.97)$ \\
\hline External pressures $*$ OII & & $0.404(0.837)$ & $-0.07^{\star *}(-2.64)$ & $-0.98^{* * *}(-13.44)$ & $0.25^{\star * *}(5.19)$ & $0.17 * * *(5.41)$ \\
\hline Managerial beliefs $*$ org. constraints & & $0.109(0.334)$ & $0.05(1.69)$ & $0.30^{\star * *}(7.98)$ & $-0.27^{\star * *}(-8.32)$ & $0.05^{\star}(2.05)$ \\
\hline Managerial beliefs $*$ financial costs & & $0.867^{\star \star}(2.420)$ & $-0.03(-0.91)$ & $0.45^{\star * *}(11.96)$ & $0.20^{\star * *}(4.79)$ & $0.26^{* * *}(9.02)$ \\
\hline Managerial beliefs $*$ OII & & $-0.540(-1.440)$ & $0.10(2.86)$ & $-0.27^{\star * *}(-6.09)$ & $-0.07(-1.70)$ & $-0.27^{\star * *}(-7.79)$ \\
\hline Group size $(N)(\%)$ & $293(100 \%)$ & $293(100 \%)$ & $88(30 \%)$ & $52(17 \%)$ & $65(22 \%)$ & $88(30 \%)$ \\
\hline$R^{2}$ & 0.281 & 0.309 & & 0.90 & 0 & \\
\hline
\end{tabular}

Note: $t$-statistics in parentheses.

${ }^{* \star *} P<0.001$.

${ }^{\star *} P<0.01$.

${ }^{*} P<0.05$. 


\begin{tabular}{|c|c|c|c|c|c|}
\hline & \multicolumn{4}{|c|}{ Segment } & \multirow[t]{2}{*}{ Single group estimates } \\
\hline & 1 & 2 & 3 & 4 & \\
\hline External pressure to move online & 6.82 & 3.46 & -0.24 & 4.13 & 2.48 \\
\hline \multicolumn{6}{|l|}{ Organizational capabilities } \\
\hline IT know-how & 0.07 & -0.14 & -0.11 & 0.60 & 0.55 \\
\hline IT infrastructure & 0.31 & 0.53 & 0.44 & 0.04 & 0.58 \\
\hline Online activity & 0.04 & 0.85 & -0.03 & -0.15 & 0.54 \\
\hline Managerial beliefs & 3.25 & -9.52 & 3.53 & 1.20 & 0.48 \\
\hline \multicolumn{6}{|l|}{ Feasibility constraints } \\
\hline Organizational & 1.48 & -8.18 & -1.72 & 1.52 & 0.63 \\
\hline Financial & 1.56 & -6.51 & 3.99 & -1.48 & 0.04 \\
\hline Operational implementation issues (OII) & -0.36 & 15.30 & -2.13 & 0.67 & 0.20 \\
\hline State of implementation & 0.05 & 0.21 & 0.61 & -0.05 & 0.63 \\
\hline \multicolumn{6}{|l|}{ Moderating effects (individual effects) } \\
\hline External pressure $\star$ managerial beliefs & -2.78 & -4.90 & -0.56 & -2.22 & 0.23 \\
\hline External pressure $\star$ organizational constraints & -0.97 & 5.15 & 4.68 & -2.61 & -2.49 \\
\hline External pressure $*$ financial costs & -1.53 & -0.69 & -6.06 & -0.63 & -6.06 \\
\hline External pressure $\star \mathrm{OII}$ & -0.84 & -11.90 & 2.90 & 1.82 & -9.84 \\
\hline Managerial beliefs $\star$ organizational constraints & 0.52 & 3.26 & -2.98 & 0.51 & 4.67 \\
\hline Managerial beliefs $\star$ financial costs & -0.33 & 5.27 & 2.20 & 2.82 & 1.14 \\
\hline Managerial beliefs $*$ OII & 1.03 & -2.82 & -0.69 & -2.53 & 9.56 \\
\hline \multicolumn{6}{|l|}{ Moderating and overall effects (grouped) } \\
\hline Overall impact of external pressure ${ }^{\mathrm{b}}$ & 3.47 & -3.98 & 1.28 & 2.70 & -8.75 \\
\hline Overall impact of managerial beliefs ${ }^{\mathrm{b}}$ & 4.47 & -3.82 & 2.06 & 2.00 & 5.81 \\
\hline Overall impact of organizational constraints ${ }^{c}$ & 1.03 & 0.23 & -0.02 & -0.58 & -4.29 \\
\hline Overall impact of financial constraints ${ }^{c}$ & -0.30 & -1.93 & 0.13 & 0.71 & -0.24 \\
\hline Overall impact of $\mathrm{OII}^{c}$ & -0.17 & 0.57 & 0.08 & -0.04 & -0.50 \\
\hline Estimated mean performance of group & 3.21 & 2.60 & 2.39 & 2.90 & 2.86 \\
\hline
\end{tabular}

${ }^{a}$ Effect sizes based on significant effects (from Table 2) are shown in bold.

${ }^{b}$ Excluding the joint effect of external pressures and managerial beliefs, but including the direct effect of the variable in question.

Including the joint effects of external pressures and managerial beliefs.

performance increases when environmental pressures are high (H1), when the IT capability within the firm is at an advanced stage $(\mathrm{H} 2)$ and when the managerial beliefs concerning the value of e-business are high (H3). On the other hand, feasibility constraints (H4) were not found to influence performance.

One of the central points of our model (Figure 1) is that the influence of external pressures on performance will be mediated by managerial beliefs. To test for mediation we follow a three-step regression method (Baron and Kenny, 1986). The results confirm the existence of a mediation effect. ${ }^{5}$ However, the presence of an interaction effect between managerial beliefs and the feasibility constraint also suggests a moderating influence between these variables. When Baron and Kenny's (1986) combined framework procedure is applied, the results confirm the existence of moderated mediation. ${ }^{6}$ In other words, the mediating effect of managerial beliefs on the relationship between environmental pressure and performance varies across different levels of organizational impediments. This result is not unexpected given increased managerial awareness of e-business and the well-documented difficulties firms experience when executing e-business strategy.

OLS regression assumes that a single model is appropriate for all firms. Given that there is no indication that this might be true, we applied latent class modeling. The identification of the segments and simultaneous estimation of coefficients within each segment allow us to identify unobserved relationships directly. The latent class models shown in Table 2 offer considerable improvement in explanation, with a 60 percentage point increase in $R^{2}$ (from 30 to $90 \%$ ) and reveal an interesting mixture of different models for different groups of firms. According to all the information criteria presented in Table 3, the foursegment solution provided the clearest between segment distinctions. This is based on a combination of the lowest 
information criteria measures, the highest entropy measure and the theoretical meaning of the results. ${ }^{7}$

Just comparing the significance of coefficients in latent class models can be misleading as the means of the dependent and independent variables will be different across the different classes. Hence, to increase the interpretability of our results, we compute 'effect size' estimates as a way of highlighting the differences between the models for each segment more effectively (see Table 4). Note that the term 'effect size' does not imply causation, it is simply statistical modeling terminology for the strength of the relationship between two variables. The effect size estimates are determined by computing the value of the estimated coefficient for each segment $\left(\beta_{i j}\right)$ multiplied by the mean for each variable $\left(\mu_{i}\right)$, where $i$ is the variable and $j$ the segment or class. This provides a more accurate picture of the contribution of that variable to the dependent variable and allows for aggregation so that direct, mediated and total effects can be distinguished more clearly. The results indicate that strong effect sizes exist on two variables in particular, external pressures to move online and managerial beliefs. In three of the four segments, the overall impact of these two variables is strongly positive. But this is only part of the narrative: each segment reveals its own story, providing additional insights that go beyond single group estimates. The rest of our discussion will rely on interpretation of Table 4.

In the case of segment 1, the highest performing group, firms are most affected by the pressure to move online and the managerial beliefs related to this. The total effect of these two variables is $7.29(=6.82+3.25-2.78)$, meaning that it is the direct and moderating effects of these two variables that drive performance. In summary, strong external pressures made the need to move towards ebusiness strategy self-evident. When combined with high managerial beliefs, the firms in this group display an ability to overcome organizational constraints that arise from competing business options.

In segment 2, the story is vastly different. These firms are driven almost exclusively by managerial beliefs, organizational and financial constraints. The total effect of these two variables is $-15.68 \quad(=-9.52-6.51-8.18+3.26+5.27)$, meaning that it is the direct and moderating effects of these implementation constraints that inhibits performance. Clearly, the managers in this segment suffer from a lack of confidence. As these firms continue to implement e-business technology, there is evidence that they have stumbled with operational implementation issues and organizational and financial constraints impair performance.

Performance in segment 3 is lower than any of the others. Although the direct effect of pressure to move online is insignificant $(-0.24)$ and that of managerial beliefs is strong (3.53), the performance effect is driven by the moderating effect of these two variables. If we compare mean performance (2.39) with the total effect of both managerial beliefs and external pressures, we see that nearly all of this is driven by these two variables $(2.78=1.28+2.06-0.56)$, leaving a slight negative impact to be picked up by the direct effect of organizational conditions and feasibility constraints. These results raise questions regarding the quality of managerial decision making; in particular, one must question why managerial beliefs are so strong when the evidence does not appear to support any such confidence.

Lastly, segment 4 , the second best performing group, faces significant pressures to move online (4.13) with slightly less overall impact from managerial beliefs. Firms in this segment are clearly sophisticated operators with a large impact from high IT know-how (0.60) and low organizational, financial and business constraints. In summary, these firms are characterized by sensible beliefs where the managers' are aware of the limits of technologybased solutions and appear to place greater importance on complementary activities and know-how.

Each of the analyses leads to important differences. To demonstrate external validity, the segments selected were evaluated against variables other than those used to generate the solution. Two analyses of this type were conducted. First, using the four-segment solution as the independent variable we ran a discriminant analysis on 'the level of investment in e-business'. The function produced discriminates between segments $(P<0.10)$ and correctly identified $88 \%$ of the cases where investment had decreased and $52 \%$ of the cases where investment had increased. Second, we used some additional variables in our survey (e.g., variables not included in the latent class) to predict membership in the four segments. This function also discriminates between segments $(P<0.02)$ and correctly identified $47 \%$ of the cases in a calibration sample (against a chance expectation of $29 \%$ ) and $34 \%$ in a cross-validation sample (against a chance expectation of $27 \%$ ). The more important variables in the function relate to the ability of the organization to adapt internal business systems to ebusiness, willingness to share data across departments and the importance of after-sales service and cross-selling competencies. These results provide some external validity to the segment solution and suggest that it is a useful guide to further our understanding of e-business performance.

\section{Discussion}

We began this paper with an important question: why does e-business performance vary between organizations that operate within the same line of business and have access to the same information and technologies? Although earlier research has examined the factors driving adoption of IT functions (e.g., relational databases, CASE and objectoriented technologies) or administrative processes (e.g., office, groupware or decision support tools), there has been little research on the drivers of more complex e-business systems (Chatterjee et al., 2002). That IT is aligned with the business is a given, but what is poorly understood is the extent to which IT business value is dependent upon organizational structures, management practices and the macro-environment (Melville et al., 2004). This paper makes a unique contribution to the e-business literature by capturing the contingent nature of these factors.

For example, the empirical results tell us that as content variables (i.e., external pressure for e-business and internal firm capabilities) vary, so too will the firm's e-business performance. More importantly, the results reveal that process variables (i.e., managerial beliefs and organizational impediments) matter most. Successful adopters quite 
clearly draw on strong beliefs and commitment by managers to an e-business future. For example, in our first OLS model the regression weights signify, with certain limitations, the importance attached to managerial beliefs. This construct explains considerable variation in performance. In the second OLS model, the influence of managerial beliefs on performance is moderated by the interaction with external pressures and financial costs. In other words, the perceived feasibility of e-business change is moderated by external factors and organizational impediments. This is entirely consistent with Swanson and Ramiller's (2004) notion of 'mindful' innovation in IT.

Furthermore, we see evidence of mindless innovation in IT (op. cit.) in the latent class segments. For example, the direct effect of managerial beliefs is strongest in segment 2 and 3 (the worst performing firms). In the case of segment 2 , managers are strongly pessimistic, while in segment 3 there is unjustified optimism. These results systematically reveal the variance and importance of managerial beliefs. Conceptually, these results also support Swanson and Wang's (2005) finding that know-how is an important driver of packaged software success. But as we know, there are many aspects of know-how that influence the success of packaged software and e-business (Lucas, 2005).

The study also hints at what we may be able to ignore. For example, data pooling techniques based on observed factors - firm size, industry type and corporate status offer little insight. Only when the unobservable factors that characterize modern business are taken into account does our model's predictive power increase. By using segmentation techniques, we are able to provide an explanation for why Hypothesis 4 was not supported in the standard regression analysis. Examination of the coefficients for each segment reveals that most paths are highly significant, but directional differences between the various segments cancel out statistical significances at the aggregate level. Clearly, hypothesis testing based on assumptions of homogeneity across a data set deserves more careful consideration.

\section{Implications for research and practice}

To the best of our knowledge, few empirical studies have integrated structural and cognitive perspectives on strategy and examined systematically the influence of hard and soft assets on e-business strategic choice. We contend that, in the absence of luck, companies interested in exploiting the value opportunities in e-business must start with a thorough analysis of hard and soft pressures to move online. The hard perspective reflects the stimulus for structural change in the organization and intervening drivers are manifested in the soft perspective. This provides advantages to academics and practitioners by helping them to understand: (a) why firms facing what appear to be similar environmental circumstances respond differently (because of different managerial beliefs), and (b) how firms can maximize the effectiveness of their strategic responses to these influences (by understanding the limits to implementation that arise in the form of organizational, financial and business impediments). These findings are consistent with research on strategic change where, despite exposing several unanswered questions, Rajagopalan and Spreitzer (1996) conclude that environmental and organi- zational conditions, managerial cognitions and managerial action are crucial constructs in explaining firm performance.

As a general rule, most researchers in IT would support the existence of sample heterogeneity; captured through a diversity of backgrounds, abilities and experiences in a survey sample. If we are to accept this logic, then it is important to identify the way performance varies in different groups or segments. The statistical basis on which our study was designed allows us to achieve this and to show how firms vary. More simplistic techniques based on data aggregation or fixed-effect models across multiple industries and organizations clearly fail to capture the degree and form of the heterogeneity that characterizes ebusiness performance. Our study provides important evidence that deterministic, single-model theories characteristic of the strategy literature are of limited usefulness when explaining and predicting e-business performance.

\section{Limitations and possible extensions}

As any study, our research has limitations that qualify our findings and present opportunities for future research. Firstly, cross-sectional designs do not enable us to explore the content of strategic change. Although it is often argued that cross-sectional designs are justified in exploratory studies that seek to identify emerging theoretical perspectives, this does not escape the inability of this type of design to fully capture the complexity in e-business strategy. Therefore, the results of this study should be viewed as preliminary evidence regarding the varying criteria of ebusiness performance. The authors recognize that stronger support for the analysis would come from measuring performance prior to and after an e-business implementation - highlighting the now customary call for the use of longitudinal studies to corroborate cross-sectional findings.

The data collection approach deserves mention. First, the dependent variable was measured using subjective assessments of a business's performance relative to other businesses in the same industry. Potential reporting biases can exist when personal judgments are used to evaluate competitive positioning in an industry. Although research has shown that self-reported performance data are generally reliable (e.g., Dess and Robinson, 1984) and represent a valid way to operationalize financial performance (Dess and Robinson, 1984; Fryxell and Wang, 1994), caution needs to be exercised in interpreting our results. Ideally, we would wish to validate and complement such measures with objective data on the excess rents earned by firms in comparison to other members of their industry, together with various operational metrics that would better explain these excess rents. The ability to measure financial and operational dimensions more fully and relative to the appropriate mix of competitors would undoubtedly provide a richer depiction of e-business performance. Unfortunately, such data are hard to obtain, partly because of the difficulty of extracting the data relevant to the business unit being studied from more aggregate corporate accounts, but also for reasons of commercial confidentiality. Indeed, it is widely accepted that firm performance is difficult to measure. Hopefully as corporate transparency increases, 
and measures such as economic value added become more available, researchers can move to address this limitation. Second, the multi-dimensional nature of several of the constructs must also be acknowledged. For example, measures of the environmental pressures construct have previously included detailed analysis of supply pressures, demand pressures and contract pressures (Devinney et al., 2000 ), and there is room for a further decomposition of the environmental pressures underlying e-business adoption.

Additionally, when moderating is at issue, the quantity and quality of data takes on greater importance (Campbell and Fiske, 1959). This implies that further independent assessment is required to demonstrate validity in our managerial beliefs construct. Further analysis of moderating effects could also be captured using path analysis techniques such as structural equation modeling. Promising applications of this technique have also been used in marketing, where models have been developed that simultaneously treat heterogeneity in the context of a specified structural equation model (Jedidi et al., 1997).

Lastly, when applying models of segmentation, one should be mindful that the results are at best workable approximations of reality. One cannot claim with complete certainty that segments exist or that the distribution of unobserved heterogeneity can be captured (i.e., that it is discrete rather than continuous). Although we have been rigorous in our approach to segmentation, latent class techniques seek only to approximate the distribution of heterogeneity. Hence, these results remain inconclusive and demand replication. Nevertheless, they do provide new insight into the factors that are likely to drive increased levels of e-business adoption across the value chain. Academics will find these results important because they provide a more systematic way to analyze the complex interaction between technology and organizational structure. This method will enable senior managers to anticipate and better plan for the e-business challenges ahead, and allow operational managers to act tactically in a way that is responsible and appropriate for the environment in which they operate.

\section{Conclusion}

Advances in e-business applications and technologies present many opportunities for contemporary businesses to redefine their strategic objectives and enhance or transform products, services, markets, work processes and business communication. By integrating strategy content and process perspectives, we begin to more fully explain why, when and how certain firms are successful with e-business systems, while others remain hesitant, unwilling or unable to change. The empirical results tell us that e-business performance differs as external pressures and capabilities (i.e., human, technological and business) vary. However, the exact extent of these capabilities is $e x$ ante indeterminant. Most importantly, the study shows that variation in managerial beliefs regarding the perceived benefit of e-business tells us much about performance. These belief structures are determined based on a shared understanding of the environmental context, the strategic orientation sought and the feasibility of executing the type of organizational change required.
Further, the cross-sectional sample of firms in our study strongly suggests that firm differences explain much of the propensity for organizational change and the e-business performance outcomes of such change. This heterogeneity is perhaps most pronounced in e-business settings where fickle markets, rapid technological change and financial constraints strongly effect the organizational reasoning that takes place to determine e-business strategy and the subsequent implications for firm development and survival. For scholars, this raises several questions concerning published studies that employ models based on mean scores that fail to take into account variance within each construct. As we have shown, directional differences exist that cancel out statistical significance at aggregate levels and therefore, potentially mask the very essence of ebusiness strategy.

\section{Acknowledgements}

This research has been supported by grants from the SAS Institute, INSEAD and the Centre for Corporate Change at the Australian Graduate School of Management. We have benefited from the comments and suggestions of Sönke Albers, Grahame Dowling, Anthony Vlasic, Torben Pedersen and participants at presentations at AGSM, Copenhagen Business School, the University of Pittsburgh, WHU-Koblenz, UCLA, INSEAD and the University of Kiel. The views expressed here are solely those of the authors, who are listed in alphabetical order.

\section{Notes}

1 See for example, Thomas et al. (2003) and numerous online industry reports such as 'Success Story', http://www.cisco.com/ web/partners/pr67/downloads/756/partnership/ibm/success/ tesco.pdf.

2 We define e-business as the interconnected fusion of IT infrastructure, business processes and organizational structure necessary to create business value. This domain captures the customized order and assembly systems used by Dell Computers, the full service Internet ordering systems pioneered by Cisco Systems, the B2B exchange offered by General Electric and the outsourcing coordination systems of Eastman Chemical.

3 The origin of content and process lie in strategic management and is relevant to any study of e-business systems where the aim is to create business value. We note that alternative theoretical bases - drawn from knowledge management and critical theory - have been published in the Journal of Information Technology to explain packaged software adoption such as ERP (Oliver and Romm, 2002; Swanson and Wang, 2005).

4 The value of these inducements can be seen by the fact that two seminars were held and were attended by nearly 500 people.

5 The first step is to regress Managerial Beliefs on Environmental Pressures. The result is found to be significant $\left(\beta=0.36^{* * *}\right.$, $t=6.61)$. Second, regressing Performance on Environmental Pressures is significant $\left(\beta=0.27^{* * *}, t=4.91\right)$. Third, regressing Performance on both Environmental Pressures and Managerial Beliefs is also significant $\left(\beta=0.10^{*}, t=2.00\right)$. Most importantly, the effect of Environmental Pressures in the third equation (Performance $=1.37+0.31 m+0.10 e)$ is less than in equation (2) above, confirming the existence of a mediating effect.

6 The technique involves regressing Performance on Managerial Beliefs, Feasibility Constraints, Environmental Pressures, 
Managerial Beliefs $*$ Feasibility Constraints, and Environmental Pressures $*$ Feasibility Constraints, where Managerial Beliefs* Feasibility Constraints is the managerial belief and feasibility constraint interaction, and Environmental Pressures $*$ Feasibility Constraints the external pressure and feasibility constraint interaction. The presence of an interaction effect between Managerial Beliefs and Feasibility Constraints, as well as a mediating effect of Managerial Beliefs on the Environmental Pressures to Performance relation, is indicative of moderated mediation. Our results confirm the existence of an interaction on Managerial Beliefs $*$ Feasibility Constraints $\left(0.86^{* *}, t=2.42\right)$ and Environmental Pressures $*$ Feasibility Constraints $\left(-0.714^{\star}\right.$, $t=-1.887)$.

7 Solutions with more than four segments are also neither parsimonious nor theoretically compelling when one looks at the segment sizes (some of which are small) and the structure of the models (which do not show greater distinctiveness in the added segments).

\section{References}

Aspesi, C. and Vardham, D. (1999). Brilliant Strategy, But Can You Execute? The McKinsey Quarterly Issue 1: 89-99.

Akaike, H. (1974). A New Look at Statistical Model Identification, IEEE Transactions on Automatic Control AC-19: 716-723.

Barney, J.B. (1991). Firm Resources and Sustained Competitive Advantage, Journal of Management 17(1): 109-120.

Baron, R.M. and Kenny, D.A. (1986). The Moderator-Mediator Variable Distinction in Social Psychological Research: Conceptual, strategic and statistical considerations, Journal of Personality and Social Psychology 51(6): 1173-1182.

Barua, A., Konana, P., Whinston, B. and Yin, F. (2004). An Empirical Investigation of Net-Enabled Business Value, MIS Quarterly 28(4): 585-620.

Bharadwaj, A.S. (2000). A Resource-Based Perspective on Information Technology Capability and Firm Performance: An empirical investigation, MIS Quarterly 24(1): 169-196.

Brynjolfsson, E. (1993). The Productivity Paradox of Information Technology, Communications of ACM 36(12): 67-77.

Brynjolfsson, E. and Hitt, L.M. (1998). Beyond the Productivity Paradox, Communications of the ACM 41(8): 49-55.

Campbell, D.T. and Fiske, D.W. (1959). Convergent and Discriminant Validation of the Multitrait-Multimethod Matrix, Psychological Bulletin 56: 81-105.

Carson, S.J., Devinney, T.M., Dowling, G.R. and John, G. (1999). Understanding Institutional Designs Within Marketing Value Systems, Journal of Marketing 63(Special Issue): 115-130.

Chan, Y.E. (2000). IT Value: The Great Divide Between Qualitative and Quantitative and Individual and Organizational Measures, Journal of Management Information Systems 16(4): 225-261.

Chatterjee, D., Grewal, R. and Sambamurthy, V. (2002). Shaping Up for eCommerce: Institutional Enablers of the Organizational Assimilation of Web Technologies, MIS Quarterly 26(2): 65-89.

Child, J. (1972). Organizational Structure, Environment and Performance: The role of strategic choice, Sociology 6(2): 1-22.

Chin, W.Y. (1998). Issues and Opinion on Structural Equation Modeling, MIS Quarterly 22(1): 7-16.

Chircu, A.M. and Kauffman, R.J. (2000). Limits to Value in Electronic Commerce-Related IT Investments, Journal of Management Information Systems 17(2): 59-80.

Clemons, E.K. and Weber, B. (1990). Strategic Information Technology Investments: Guidelines for decision making, Journal of Management Information Systems 7(2): 9-28.

Coltman, T.R., Devinney, T.M. and Midgley, D.F. (2005). Strategy Content \& Process in the Context of E-Business Performance, in G. Szulanski (eds.) Strategy Process, Advances in Strategic Management, Vol. 22. New York: JAI Press, pp. 349-386.

CSC Index (1994). State of Reengineering Report, Cambridge, MA: Forrester Research Inc.
Dess, G. and Robinson, R.B. (1984). Measuring Organizational Performance in the Absence of Objective Measures: The case of the privately-held firm and conglomerate business unit, Strategic Management Journal 5(3): 265-274.

Devinney, T.M., Midgley, D.F. and Venaik, S. (2000). The Organizational Imperative and the Optimal Performance of the Global Firm: Formalizing and extending the integration-responsiveness framework, Organization Science 11(6): 674-695.

DiMaggio, P.J. and Powell, W.W. (1983). The Iron Cage Revisited: Institutional isomorphism and collective rationality in organizational fields, American Sociological Review 48(2): 147-160.

Finkelstein, S. and Hambrick, D.C. (1996). Strategic Leadership: Top Executives and Their Effects on Organizations, St Paul, MN: Printwise.

Fornell, C. and Larcker, D.F. (1981). Evaluating Structural Equation Models with Unobservable Variables and Measurement Error, Journal of Marketing Research 18(2): 39-50.

Fryxell, G.E. and Wang, J. (1994). The Fortune Corporate 'Reputation' Index: Reputation for what? Journal of Management 20(1): 14.

Hamel, G. and Prahalad, C.K. (1994). Competing For the Future, Harvard Business Review 72(3): 122-128.

Hatten, K.J., Schendel, D.E. and Cooper, A.C. (1978). A Strategic Model of the US Brewing Industry: 1952-1971, Academy of Management Journal 21(4): 592-610.

Henderson, J.C. and Venkatraman, N. (1993). Strategic Alignment: Leveraging information technology for transforming organizations, IBM Systems Journal 32(1): 4-16.

Huff, A.S. and Reger, R.K. (1987). A Review of Strategy Process Research, Journal of Management 13(2): 211-236.

Ives, B. (1994). Probing the Productivity Paradox, MIS Quarterly 18(2): 21-24.

Jedidi, K., Jagpal, H.S. and DeSarbo, W.S. (1997). Finite-Mixture Structural Equation Models for Response-Based Segmentation and Unobserved Heterogeneity, Marketing Science 16(1): 39-59.

Johnston, R.H. and Carrico, S.R. (1988). Developing Capabilities to Use Information Strategically, MIS Quarterly 12(1): 37-47.

Kohli, R. and Devaraj, S. (2003). Measuring Information Technology Payoff: A meta analysis of structural variables in firm-level empirical research, Information Systems Research 14(2): 127-145.

Lazarfeld, P.F. and Henry, N.W. (1968). Latent Structure Analysis, Boston: Houghton Mifflin.

Lewis, W., Agarwal, R. and Sambamurthy, V. (2003). Sources of Influence on Beliefs and IT Use: An empirical study of knowledge workers, MIS Quarterly 27(4): 657-678.

Lucas, H.C. (2005). Information Technology: Strategic Decision Making for Managers, New York: NY, John Wiley.

McCutcheon, A.C. (1987). Latent Class Analysis, Beverly Hills, CA: Sage Publications.

Melville, N., Kraemer, K. and Gurbaxani, V. (2004). Information Technology and Organizational Performance: An integrative model of IT business value, MIS Quarterly 28(2): 283-322.

Oliver, D. and Romm, C. (2002). Justifying Enterprise Resource Planning Adoption, Journal of Information Technology 17(4): 199-213.

Pettigrew, A.M. (1992). The Character and Significance of Strategy Process Research, Strategic Management Journal 3(Special Issue): 5-16.

Podsakoff, P. and Organ, D. (1986). Self Reports in Organizational Research: Problems and prospects, Journal of Management 12(4): 531-544.

Porter, M.E. (1985). Competitive Advantage: Creating and Sustaining Superior Performance, New York, NY: Free Press.

Porter, M.E. (2001). Strategy and the Internet, Harvard Business Review 79(3): 63-78.

Priem, R.L. and Butler, J.E. (2001). Is the Resource-Based View a Useful Perspective for Strategic Management Research? Academy of Management Review 26(1): 22-40.

Rajagopalan, N. and Spreitzer, G.M. (1996). Toward a Theory of Strategic Change: A multi-lens perspective and integrative framework, Academy of Management Review 22(1): 48-79.

Robinson, J.P., Shaver, P.R. and Wrightsman, L.S. (1991). Criteria for Scale Selection and Evaluation, in J.P. Robinson, P.R. Shaver and L.S. Wrightsman (eds.) Measures of Personality and Social Psychological Attitudes, San Diego, CA: California Academic Press, pp. 1-15.

Rossiter, J.R. (2002). The C-OAR-SE Procedure for Scale Development in Marketing, International Journal of Research in Marketing 19(4): 1-31. 
Santhanam, R. and Hartono, E. (2003). Issues in Linking IT Capability to Firm Performance, MIS Quarterly 27(1): 125-153.

Swanson, E.B. and Ramiller, N.C. (1997). The Organizing Vision in Information Systems Innovation, Organization Science 8(5): 458-474.

Swanson, E.B. and Ramiller, N.C. (2004). Innovating Mindfully with Information Technology, MIS Quarterly 28(4): 553-584.

Swanson, E.B. and Wang, P. (2005). Knowing Why and How to Innovate with Packaged Business Software, Journal of Information Technology 20(1): 20-31.

Teece, D.J., Pisano, G. and Shuen, A. (1997). Dynamic Capabilities and Strategic Management, Strategic Management Journal 18(7): 509-533.

Thomas, J., Reinartz, W. and Kumar, V. (2003). Getting the Most Out of All Your Customers, Harvard Business Review 82(7): 116-124.

Thompson, A.A. and Strickland, A.J. (2001). Crafting and Executing Strategy, Singapore: McGraw-Hill, Irwin.

Thurow, L.C. (1991). Forward, in M. Scott-Morton (ed.) The Corporation of 1990's: Information Technology and Organizational Transformation, New York, NY: Oxford University Press, pp. v-vii.

Tippins, M.J. and Sohi, R.S. (2003). IT Competency and Firm Performance: Is organizational learning a missing link? Strategic Management Journal 24: 745-761.

Varadarajan, P.R. (1999). Strategy Content and Process Perspectives Revisited, Academy of Marketing Science Journal 27(1): 88-101.

Venkatraman, N. (1997). Beyond Outsourcing: Managing IT as a value centre, Sloan Management Review 38(3): 51-64.

Venkatraman, N. and Ramanujam, V. (1986). Measurement of Business Performance in Strategy Research: A comparison of approaches, Academy of Management Review 11(4): 801-814.

Wade, M. and Holland, J. (2004). The RBV and IS Research: Review, extension and suggestions for future research, MIS Quarterly 28(1): 107-142.

Wedel, M. and Kamakura, W. (2000). Market Segmentation, London: Kluwer. Wernerfelt, B. (1984). A Resource-Based View of the Firm, Strategic Management Journal 5(2): 171-181

\section{About the authors}

Tim Coltman has a $\mathrm{PhD}$ in strategic management and marketing from the Australian Graduate School of Management (AGSM). He has published in leading journals such as California Management Review, Advances in Strategy and Communications of the ACM. He currently holds an
Australian Research Council Fellowship where he is engaged in pioneer supply chain management research for DHL and BlueScope Steel. Previously, he has completed research projects in e-business and customer relationship management for organizations such as the SAS Institute, SAP, Fairfax Business Research and MIS magazine. Tim has more than 10 years experience in the IT industry, having worked as a senior project manager within private consultancy, government and higher education.

Timothy M Devinney is a Professor of Strategy at the Australian Graduate School of Management and Director of its Centre for Corporate Change. He has published in many leading journals including Management Science, Organization Science, Academy of Management Review, Strategic Management Journal, California Management Review and Journal of Marketing to name only a few. He has MA, MBA and $\mathrm{PhD}$ degrees from the University of Chicago and a BSc from Carnegie Mellon University.

David Midgley joined INSEAD in 1999 as Professor of Marketing after holding positions at the Anderson School, University of California, Los Angeles and the Australian Graduate School of Management, Sydney. From 2001 to 2005 he was elected Head of the Marketing Area at INSEAD. $\mathrm{He}$ has over 80 publications, including papers in leading journals such as the Journal of Consumer Research, Journal of International Business, Journal of Marketing Research, Journal of Marketing, Marketing Science and Management Science and Organization Science. He was on the editorial board of the Journal of Consumer Research from 1983 to 1999 and is currently on the editorial board of the International Journal of Research in Marketing. His principal areas of research interest are innovation, global strategy and e-business.

\section{Appendix A}

Questionnaire items and constructs

\section{External Pressures}

a. Market, technological and/or environmental pressures are moving my firm towards: less (1) or more (5) online services and/or products

\section{Organisational Capabilities}

IT and Customer Service Application Know-How (small=1; large=5)

a. Extent of information technology capability

b. Extent of customer/partner service applications (ordering, customer/partner care and billing applications) capability

IT Infrastructure (Not used=1; Extensively used=5)

a. Indicate the level of e-mail, Intranet, and Internet application usage.

Level of Online Activity ( $0=$ no activity; $10=$ only online activity)

a. What is the relative amount of B2B activity in comparison to your bricks and mortar activity?

b. What is the relative amount of B2C activity in comparison to your bricks and mortar activity?

c. What is the relative amount of B2G activity in comparison to your bricks and mortar activity? 
Feasibility Constraints ( $1=$ strongly disagree; $5=$ strongly agree)

Organizational Inertia

a. Gaining consensus among the key decision makers in my organization is a major hurdle in deciding on new business strategies.

b. When deciding amongst strategic alternatives in my firm, political influence and parochial interest play a crucial role.

\section{Financial Constraints}

a. In your business unit, to what extent has the cost of infrastructure constrained your organization's ability to develop an integrated approach to customer data management and customer web interaction?

b. In your business unit, to what extent has the cost of IT personnel constrained your organization's ability to develop an integrated approach to customer data management and customer web interaction?

Operational Implementation Issues

a. To what extent have decisions regarding the implementation of an e-intelligence strategy been influenced by network performance problems?

b. To what extent have decisions regarding the implementation of an e-intelligence strategy been influenced by information security?

c. To what extent have decisions regarding the implementation of an e-intelligence strategy been influenced by brand protection?

d. To what extent have decisions regarding the implementation of an e-intelligence strategy been influenced by customer privacy?

State of Implementation (4 discrete non-inclusive choices)

a. Identify the strategic option that best reflects your business unit's current e-business: e-business operations are still at the pilot program stage; e-business has been integrated into the core systems in my unit but its success is still uncertain; e-business has been successfully integrated into the core systems in my unit; e-business operations proved to be inappropriate or unprofitable and have been wound down (e.g., either closed or divested).

Managerial Beliefs ( $1=$ to a small extent; $5=$ to a large extent)

a. To what extent do you believe the Internet is improving the competitive standing of your firm?

b. To what extent would relationships with major customers/partners have suffered if we had not implemented e-business initiatives?

c. To what extent is it easy to see how e-intelligence systems would create new value for our major customers/partners?

d. To what extent will customers and trading partners recognize the opportunity for joint profit as a result of my business unit's e-intelligence strategy?

e. In the next two years it is my expectation that the application and development of web-based systems in my firm will have a relatively minor/major strategic impact.

\section{Performance}

Financial Profitability ( $1=$ dramatically failed; $5=$ far exceeded)

a. To what degree have your expectations been met in return on investment (after tax)?

b. To what degree have expectations been met in terms of market share?

c. To what degree have expectations been met in terms of sales?

d. To what degree have expectations been met in terms of the cost of transactions with customers?

e. To what degree have expectations been met in revenue growth?

Operational Benefits ( $1=$ to no extent; $5=$ to a great extent)

a. To what extent have e-business applications provided benefits in terms of new customer insights?

b. To what extent have e-business applications provided benefits in terms of targeting customers?

c. To what extent have e-business applications provided benefits in terms of faster response times?

d. To what extent have e-business applications provided benefits in terms of customized products and services?

e. To what extent have e-business applications provided benefits in terms of information access?

f. To what extent have e-business applications provided benefits in terms of reduced service costs? 